\title{
Esophageal Varices from Alcohol-Induced Liver Cirrhosis: Autopsy-Based Case Study of Morphologic Changes of Organs
}

\author{
Paul Poku Sampene Ossei ${ }^{1}$,Eric Agyeman-Duah*1, Moses Babatunde Duduyemi' ${ }^{1}$, Nicholas Akinwale Titiloye ${ }^{1}$, \\ Elizabeth Akosua Brefo ${ }^{2}$ and Eric Asare Fenteng ${ }^{1}$ \\ ${ }^{1}$ Department of Pathology, Komfo Anokye Teaching Hospital/Kwame Nkrumah University of Science and Technology, Africa \\ ${ }^{2}$ School of Medical Sciences, Kwame Nkrumah University of Science and Technology, Africa
}

Submission: October 01, 2017; Published: October 12, 2017

*Corresponding author: Eric Agyeman-Duah, Department of Pathology, KomfoAnokye Teaching Hospital/Kwame Nkrumah University of Science and Technology, Kumasi, Ghana, Africa, Email: saxcess21@gmail.com

\begin{abstract}
Chronic abuse of alcohol has been attributed to 3.8\% global deaths and 4.6\% disability-adjusted life years. Studies over the years have attributed chronic alcoholism as a major risk factor to liver cirrhosis. This study profiles morphologic changes of some internal organs associated with esophageal varices as observed during autopsy examination. Morphological changes of internal organs with pathologic significance were observed in the hepatobiliary, lympho-recticular and gastrointestinal systems. Morphological changes were observed in the liver, esophagus, stomach, intestines and spleen which confirm alcohol-induced liver cirrhosis as the contributing pathology of esophageal varices.
\end{abstract}

Keywords: Alcohol; Cirrhosis; Esophageal varices; Autopsy

\section{Introduction}

Alcohol remains one of the most abused substances worldwide. Chronic abuse of alcohol has been attributed to $3.8 \%$ global deaths and $4.6 \%$ disability-adjusted life years [1]. Several reports in Africa have shown the extensive abuse of alcohol. Ghana is a major culprit to this menace as some reports have shown the abuse of alcohol, even by minors ( $<18 y e a r s)$, for many daft reasons such as aphrodisiac [2-4]. Alcohol abuse has been reported to be one of the major causes of medicolegal death in Ghana [5] Studies over the years have attributed chronic alcoholism as a major risk factor to liver cirrhosis [6,7]. Patients with liver cirrhosis develops portal hypertension which put them at a higher risk of sustaining esophageal varices. Over $80 \%$ of patients with liver cirrhosis are likely to develop esophageal varices - conditions that culminate to sudden death via gastrointestinal bleed $[8,9]$. This study profiles morphologic changes of some internal organs associated with esophageal varices as observed during autopsy examination.

\section{Case Report}

The deceased, a 53 year-old man with history of chronic alcoholism, was reported to have been found dead in front of his room at dawn. The family recount that prior to his death, he experienced episodes of vomiting blood which he was later advised by a medical practitioner to avoid drinking alcohol but he declined.

\section{Autopsy Findings}

External Findings: The body is of a mid-aged man of normal posture. He is about $1.72 \mathrm{~m}$ in height, looks markedly wasted, icteric and pale. There were no marks of violence on the body as well as no sign of early decomposition. The eyes are slightly closed with completely closed mouth. The deceased has no dentures on the upper teeth and these are well tended to, Presence of blood clot on the lower lip (Figure 1).

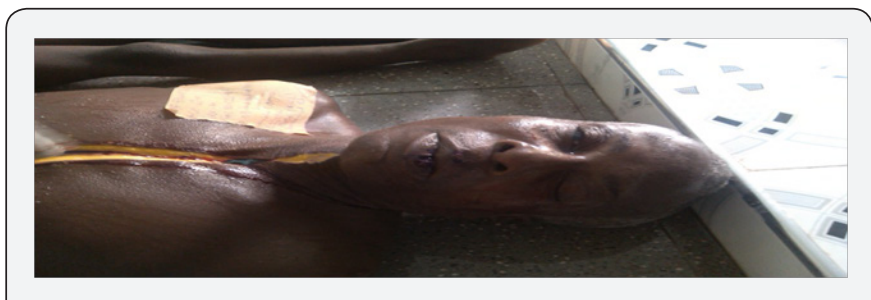

Figure 1: Autopsy examination of external features of deceased.

Internal Findings: Morphological changes of internal organs with pathologic significance were observed in the hepatobiliary, lympho-recticular and gastrointestinal systems 


\section{Journal of Forensic Sciences \& Criminal Investigation}

(Figure 2). Normal findings were seen in the remaining systems such as the cardiovascular and respiratory systems.

Hepatobiliary System: The liver weighed 1900g with a rough surface. The coarse surface is due to the presence of mixture of micro and macronodules of about 0.3 and $0.75 \mathrm{~cm}$ in diameter respectively. Both the outer and cut surface of the liver shows tan-yellow appearance and firm to touch (Figure 3).

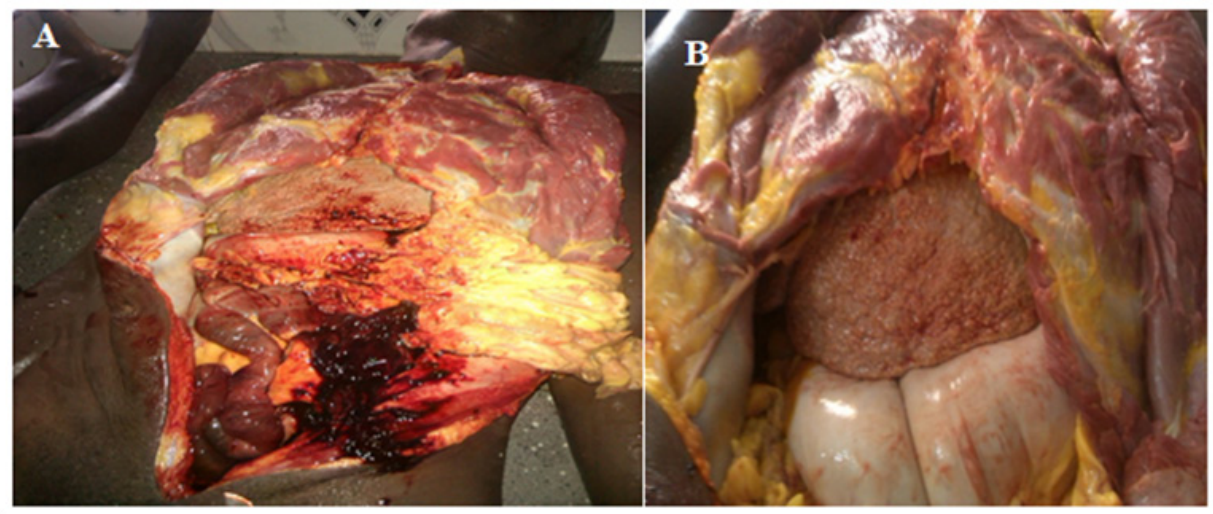

Figure 2: Examination of some abdominal $(A)$ and thoracic $(B)$ organs.
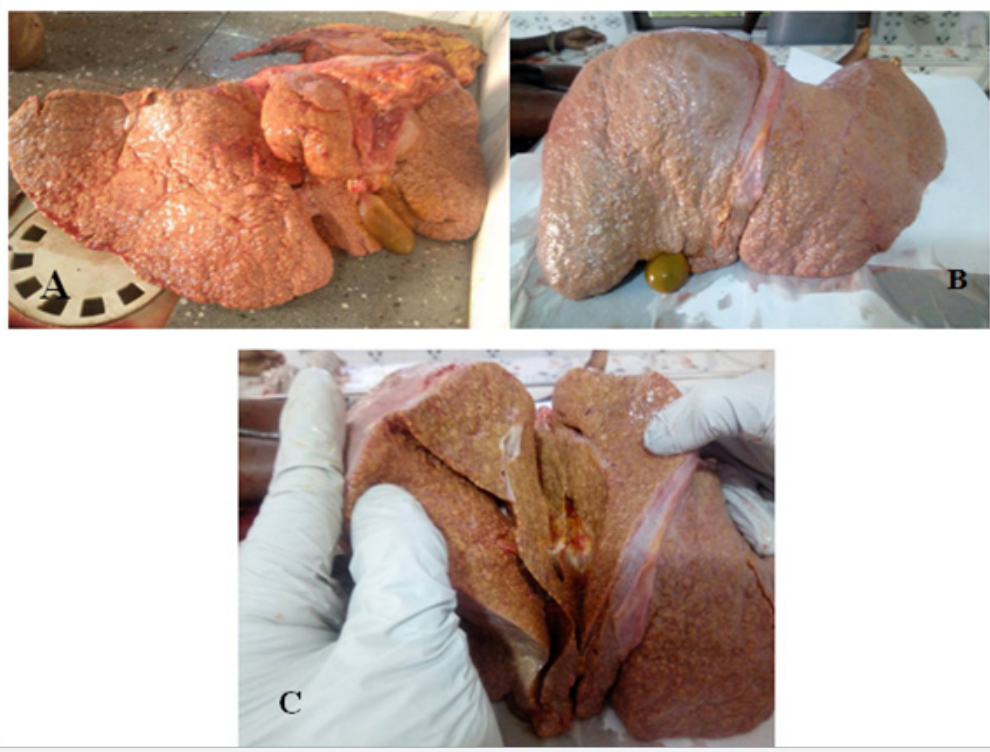

Figure 3: Morphologic changes to the external (A and B) and internal (C) parts of the liver.

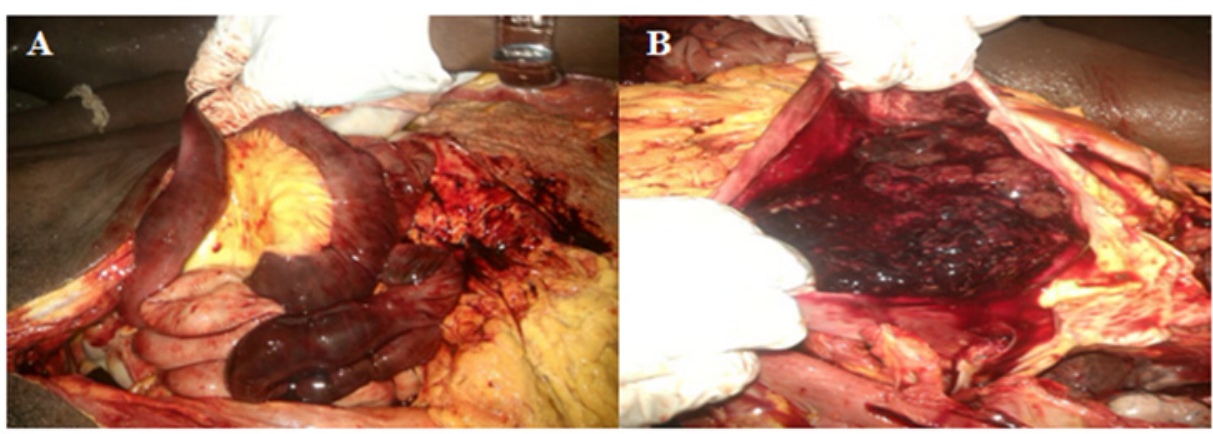

Figure 4: Massive bleed into the intestines (A) and the stomach (B).

How to cite this article: Ossei P P S, Agyeman-Duah E, Duduyemi M B, Titiloye N A, Brefo E A ,et al. Esophageal Varices from Alcohol-Induced Liver Cirrhosis: Autopsy-Based Case Study of Morphologic Changes of Organs. J Forensic Sci \& Criminal Inves. 2017; 5(5): 555674. DOI: 10.19080/ JFSCI.2017.05.555674. 
Gastrointestinal System: The lower part of the esophagus and the small intestine had coffee-brown appearance. Sections showed hemorrhage, necrosis and partly fatty in cut surfaces. There was evidence of rupture of veins in the sub mucosa of esophagus with some thrombi. Fatty nodular lesions were present in the parenchyma. There was massive bleed into the stomach and the small intestine (Figure 4).

Lymphorecticular system: The spleen was markedly enlarged.

\section{Conclusion}

The cause of death was:

\section{Haemorrhagic shock}

a. Massive intragastric bleed

b. Ruptured esophageal varices

II. Liver cirrhosis

III. Natural

\section{Discussion}

Persistent alcohol abuse for a long period of time has a devastating effect on the liver. Major complications include hepatic steatosis, alcohol hepatitis and cirrhosis. About 20 to $25 \%$ of chronic alcoholics have been reported to have liver cirrhosis. This is an alarming prevalence and poses a major public health challenge in most countries especially those in Africa. Alcohol-induced liver cirrhosis usually begins with fatty liver disease or steatosis. Alcohol abuse within a short period of time $(80 \mathrm{~g} /$ day $)$ induces mild but reversible changes to the liver. Fatty liver is a reversible hepatic changes usually encountered. Long term abuse of alcohol leads to alcohol-induce liver cirrhosis. The onset of liver cirrhosis is dependent on the type of alcoholic drink abused gender, genetic factors and the quantity of daily alcohol intake $[10,11]$.

Patients with alcohol-induced liver cirrhosis may present clinical symptoms such as distended abdomen, wasted extremities, malaise, weakness, weight loss and ascites. A major life-threatening complication of liver cirrhosis is esophageal varices. About $90 \%$ of patient with liver cirrhosis develops esophageal varices. This is usually asymptomatic and is only diagnosed only during autopsy. It is a fatal complication to portal hypertension among cirrhotic patients [10].

Venous blood from portal vein moves to the liver and to vena cava. Pathologic conditions such as liver cirrhosis blocks this movement of blood from portal vein to the liver. The blockage leads to development of portal hypertension. Portal hypertension triggers collateral channels to develop and this shunt blood directly to the vena cava without passing through the liver. Esophagus is one of the few organs where collateral channel are formed. The portal hypertension dilate collateral or anastomosis channels in submucosa of esophagus while culminate to rupture and massive gastrointestinal bleed. Other morphological changes of portal hypertension include expanding parenchymal nodules and perivenular fibrosis. The nodules may present as micronodules or macronodules depending on the chronicity of the condition. Other clinical consequences of portal hypertension include splenomegaly, ascites and hepatic encephalopathy [10-13].

The autopsy showed massive intragastric and intestinal bleed. From esophageal varices. This was due to the liver cirrhosis. Though liver cirrhosis have diverse risk factors, the clinical, police and family reports confirm chronic alcohol abuse as the major cause of the liver cirrhosis in the deceased. With the eminent abuse of alcohol in Ghana, the incidence of this condition is expected to increase in the country. The abuse of alcohol even by minors poses an economical challenge to the nation with life-expectancy projected to be reduced if alcohol abuse is not handled properly.

\section{Conclusion}

Alcohol abuse has devastating effect on human lives especially in developing countries. It is evident that deceased died from haemorrhagic shock which began with alcoholinduced liver cirrhosis. With the rising incidence of alcohol abuse in Ghana and Africa at large (even by minors), the incidence of esophageal varices is likely to increase over the years which will become a major health public health and economic challenge in Africa. Proper measures must be taken to regulate the alcohol intake to avoid complications.

\section{References}

1 Williams MF (2014) Outpatient management of adult alcoholism SAMJ: South African Medical Journal 104(1): 73-74.

2 Heise L (1992) Alcoholism in Africa. The African Mirror 2(4): 12-14.

3 http://citifmonline.com/2017/04/28/adonko-bitters-recalled-overdrunk-minors-angel-group-fined-ghc25000/

4 http://www.graphic.com.gh/news/general-news/fda-orders-recallof-adonko-bitters-over-drunken-youth.html

5 Ossei PPS, Agyeman-Duah E (2017) Trend of Medicolegal Manner of Deaths in Ghana: A Forensic Autopsy-Based Study. Ann Int Med Den Res 3(4): 56-61.

6 Tsokos M, Türk EE (2002) Esophageal variceal hemorrhage presenting as sudden death in outpatients: A study of 45 medicolegal autopsy cases. Archives of pathology \& laboratory medicine 126(10): 11971200.

7 Sung Ui Shin, Jeong-Min Lee, Mi Hye Yu, Jeong Hee Yoon, Joon Koo Han, et al. (2014) Prediction of esophageal varices in patients with cirrhosis: usefulness of three-dimensional MR elastography with echoplanar imaging technique. Radiology 272(1): 143-153.

8 González-Ojeda A, Cervantes-Guevara G, Chávez-Sánchez M, DávalosCobián C, Ornelas-Cázares, et al. (2014) Platelet count/spleen diameter ratio to predict esophageal varices in Mexican patients with hepatic cirrhosis. World Journal of Gastroenterology: WJG 20(8): 2079-2084.

9 Zhuang ZH, Lin AF, Tang DP, Wei JJ, Liu ZJ, et al. (2016) Association of Endoscopic Esophageal Variceal Ligation with Duodenal Ulcer. Journal of the College of Physicians and Surgeons--Pakistan: JCPSP, 26(4): 267271. 
10 Kumar V, Abbas AK, Aster JC (2013) Robbins Basic Pathology, ( $9^{\text {th }}$ edn) Elsevier Saunders, Philadelphia, USA, pp. 607-609.

11 Anderson JR (1974) Muir's Textbook of Pathology. (10 ${ }^{\text {th }}$ edn), Edward Arnold Publishers, Bedford, London, pp. 538-603.

12 Underwood JCE (1992) General and Systemic Pathology, Churchill Livingstone, New York, USA, pp. 353-400
13 Finkbeiner WE, Ursell PC, Davis CL (2004). Autopsy Pathology: A manual and atlas. ( $1^{\text {st }}$ edn), Churchill Livingstone, Philadelphia, USA, pp. 231-232.

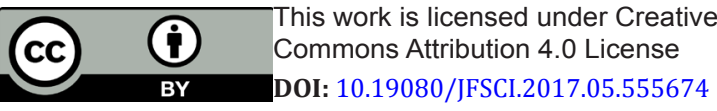

\section{Your next submission with Juniper Publishers will reach you the below assets}

- Quality Editorial service

- Swift Peer Review

- Reprints availability

- E-prints Service

- Manuscript Podcast for convenient understanding

- Global attainment for your research

- Manuscript accessibility in different formats ( Pdf, E-pub, Full Text, Audio)

- Unceasing customer service

Track the below URL for one-step submission https://juniperpublishers.com/online-submission. 